\title{
The Attractive Effects of Amino Acid and Some Classical Substances on Grass Carp (Ctenopharyngodon Idellus)
}

\author{
Haojie Yu \\ hua zhong nong ye da xue: Huazhong Agriculture University

\section{Xiaoyu Wang} \\ hua zhong nong ye da xue: Huazhong Agriculture University

\section{Fanshuang Kong} \\ hua zhong nong ye da xue: Huazhong Agriculture University \\ Qingsong Tan ( $\sim$ qstan@hotmail.com) \\ Huazhong Agricultural University https://orcid.org/0000-0002-8255-2380
}

\section{Research Article}

Keywords: Behavioral test, Electro-olfactogram, Feeding attractant, Ctenopharyngodon idellus

Posted Date: March 31st, 2021

DOI: https://doi.org/10.21203/rs.3.rs-355060/v1

License: (a) This work is licensed under a Creative Commons Attribution 4.0 International License. Read Full License

Version of Record: A version of this preprint was published at Fish Physiology and Biochemistry on July 31st, 2021. See the published version at https://doi.org/10.1007/s10695-021-00990-1. 


\section{Abstract}

Grass carp (Ctenopharyngodon idellus) is one of the most essential fishing species in China. The bait for this fish is rapidly developing. However, the study on the attractants in the bait for this fish lacks. This study was designed to systematically investigate the effects of 16 kinds of stimuli on the perspective of behaviour and physiology of grass carp by using different kinds of methods, including behavioral tests (maze test and biting-balls test) and electro-olfactogram (EOG). Our experiment's idea is mainly to imitate: in addition to vision, fish in nature also use smell to find food and finally swallow under the action of olfaction, taste and other sensory systems. Firstly, the behavioral maze test was used to screen the attractive or suppressive effect of 16 stimuli on grass carp and the electronic olfactory recording method was used to further evaluate the olfactory response of grass carp to the eight stimuli selected from the maze test. Then, the best concentrations of these eight stimuli and their combination were investigated by the biting-balls test to compound a formula with the strongest appetite for grass carp. The results of behavioral maze test showed that DMPT, DMT, glycine, Taurine, L-glutamic, L-alanine, L-proline, L-arginine have different degrees of useful in attracting grass carp. The electroolfactogram recoding showed that the EOG response of grass carp to the stimuli is a transient biphasic potential change and all of the eight stimuli could induce the EOG response of grass carp. The biting-balls test showed that glycine, L-glutamic, L-arginine at $10^{-2} \mathrm{~mol} / \mathrm{L}$ had significant feeding stimulation and DMT at $10^{-1} \mathrm{~mol} / \mathrm{L}$ had significant feeding stimulation than the other groups. Finally, formula 9 composed of DMT, glycine, Lglutamic acid and L-arginine has the greatest attraction for grass carp. The results of this study verified the attractive effect of some amino acids and other chemicals on grass carp fishing, and would provide support for the production of specific grass carp attractants.

\section{Introduction}

China has a long history of fishing with bait. With the continuous development of the economy and the improvement of people's living conditions, the sport of fishing has flourished in China. Grass carp (Ctenopharyngodon idellus) is one of the essential fishing species in China. Most anglers use some natural baits, such as corn and aquatic plants, which are not effective in attracting the grass carp. The commercial bait is composed of foodbased basic materials and attractants, among which the attractants play a decisive role in the entire bait (Løkkeborg and Johannessen 1992). The feeding activity of grass carp was improved by adding amino acids and other stimuli to the bait made from food-based basic materials so that the angler can better enjoy the fun of fishing.

In previous studies, the olfactory systems of various fishes have been shown to be highly sensitive to chemical stimuli (Hara 1975; Franklyn et al. 2017; Kasumyan and Mikhailova 2017; Hu et al. 2021). The olfactory epithelium of fish is similar in structure to that of other vertebrates. However, because olfaction of fish takes place in an aquatic medium, a wide variety of compound classes are sensitive stimuli (Ozorio et al. 2010). Among these soluble compounds are amino acids, which have been demonstrated to be feeding cues and function as potent olfactory stimuli. L-type amino acids are recognized as effective phagosomes in fish (Franklyn et al. 2017). L-cysteine, L-alanine, L-lysine, L-proline induce bottom searching in rainbow trout (Oncorhynchus mykiss), and L-arginine, L-glutamate, L-proline cause a pecking behavior in goldfish (Carassius auratus Linnaeus) (Hara 2010). These findings have been clarified from the electric physiological experiment results for rainbow trout (Hara 1994) and channel catfish (Ictalurus punctatus). Studies on substances other than amino acids have shown that dimethylthetin (DMT) could act as an effective feeding stimuli in high plant-based diets for juvenile GIFT tilapia (Oreochromis sp) (Zou et al. 2017). Dimethyl- $\beta$-propiothetin (DMPT) is not only a strong olfactory stimulant but also a $\left(\mathrm{CH}_{3}\right)_{2} \mathrm{~S}$ group donor, which is a crucial group that activates animal taste receptors (Olsén et al. 2018). It shows a robust promoting effect on feeding and growth in a variety of fish species, and its feeding stimulating impact is 2.5 times that of glutamine (Kenji et al. 1989). It has been confirmed that trimethylamine N-oxide (TMAO) can be used as a feeding attractant in the feed for Penaeus vanname (Zhang et al. 2005). In previous studies, the amino acid mixture was found to function more efficiently than single amino acids as a stimulus (Lim et al. 2015).

The current research on fish attractions is mainly based on the behavioral test (Miyasaki et al. 1999) and electrophysiological test (Jiesheng and John 1991). Previous studies mostly used a single method to study the effect of attractants. The experimental results of the fish behavioral test are different from the electrophysiological test results, and the electrophysiological results alone are difficult to distinguish, which is a useful attractant substance.

At present, there are relatively few studies on attractants for grass carp diet and bait. Besides, the attraction effect of commercial grass carp bait is not apparent for fishing. It is deserved to develop a special attractant for grass carp. The present study is the first time to study the attractants of grass carp using different methods systematically. The aim of the present study was to screen several substances that have an attractive effect on grass carp from 16 stimuli through the behavioral maze test, then to explain the stimuli effect of the selected substances on grass carp from a physiological point of view using EOG test and finally to determine the optimal concentration of each stimulus and the optimized formula of compound attractants through an orthogonal design using the behavioral biting-balls test.

\section{Material And Methods}

\subsection{Grass carp maintenance}

Young grass carp (Ctenopharyngodon idellus, body weight: $30 \pm 5 \mathrm{~g}$ ) were purchased from Honghu Fisheries Co. Ltd.,. The fish were cultured in a $\operatorname{tank}(300 \mathrm{~L})$ with circulating filtered and aerated $(>24 \mathrm{~h})$ tap water $(\mathrm{pH} 7.0-7.4)$ in a temperature-controlled room $\left(25 \pm 1^{\circ} \mathrm{C}\right)$ before the experiment. 
Water quality parameters, including $\mathrm{pH}$, temperature, and dissolved oxygen (> $6 \mathrm{mg} / \mathrm{L}$ ), were measured weekly. The fish were fed with a commercial grass carp diet twice a day, at 9:00 am and 4:00 pm, respectively. The faeces and debris in the bottom were cleared daily.

\subsection{The behavioral maze test}

An experimental aquarium (Fig. 1), designed according to K Harada (Harada 1982), was made of tempered glass, composed of two resident compartments ( 1 and 2 in Fig. 1 ) and four test compartments to conduct a duplicate test, $h$ is elliptical holes ( $a=5 \mathrm{~cm}, b=8 \mathrm{~cm}$ ) provided on the septa to restrict cluster access to the test compartments. The experimental aquarium with a water depth of $35 \mathrm{~cm}$ was set in an air-conditioned room (water temperature: $25 \pm 0.5^{\circ} \mathrm{C}$ ). Thirty individuals of fish in each resident compartment were used in the test.

The maze test was conducted as follows, 16 kinds of feeding stimuli consisted of food grade chemicals L-alanine, L-arginine, L-cysteine, L-glutamic acid, glycine, L-histidine, L-lysine, L-methionine, L-phenylalanine, L-proline, L-threonine, L-valine and taurine (Hebei Wubai Technology Co., Ltd), dimethyl- $\beta$-propiothetin (DMPT), dimethylthetin (DMT) and trimethylamine N-oxide (TMAO) (Beijing Green Hengxing Biotechnology Co., Ltd), were tested for the estimation of repellence or attraction. For each stimulant, $10^{-1} \mathrm{~mol} / \mathrm{L}$ solution was prepared, and then $16 \mathrm{~g}$ of wheat flour and $8 \mathrm{~mL}$ of stimulant solution were thoroughly mixed and made into a test bait ball. The control ball (wheat flour bait without stimulant addition) was used as a dummy. The test/control ball was wrapped in two layers of gauze $(8 \mathrm{~cm} \times 8 \mathrm{~cm})$. The wrapped gauze was quietly hung on the $S$ position of the test compartments. Freshwater was introduced continuously into the aquarium through each inlet of the delivery tube at the rate of $500 \mathrm{~mL}$ per minute. During the test, a control and a test bait ball wrapped with gauze were randomly put into the two test compartments corresponding to the same resident compartment simultaneously, with one ball in one of the test compartment at the S-position. After the inlet water rinsed the wrapped gauze to deliver the stimuli into the entire test compartment for $1 \mathrm{~min}$, the partition $\mathrm{P}$ was removed. The fish in the resident compartment were allowed to enter and left the two test compartments freely. The fish entering and leaving the test compartments was continuously recorded for 10 min using a camera (TL-IPC42A-4, TP-LINK). In this context, each batch of the fish, which entered, left and remained in each test compartment, were counted for 10 min at every one-minute interval. The numbers of fish entered, left, and remained counted every one min in each test compartment were summed up to represent $\mathrm{y}_{E \llbracket x}, \mathrm{y}_{\square \rrbracket x}$ and $\mathrm{y}_{\mathrm{R}[\mathrm{x}}$, respectively. Furthermore, the entered, the left and the remained numbers summed up were successively integrated with

passing the time to represent

$$
\mathrm{Y}_{\mathrm{E} \cdot \mathrm{x}}=\sum_{\mathrm{X}=1}^{\mathrm{i}} y_{E \cdot \mathrm{x}}, \mathrm{Y}_{\mathrm{L} \cdot \mathrm{x}}=\sum_{x=1}^{i} y_{L \cdot \mathrm{x}} \text { and } \mathrm{Y}_{\mathrm{R} \cdot \mathrm{x}}=\sum_{\mathrm{X}=1}^{\mathrm{i}} y_{R \cdot \mathrm{x}}
$$

each behavior per minute is accumulated and represented by a logistic curve $Y=g /\{1+\exp [-r(x-a)]\}$, where the coefficients $g$, $r$ and a are constants. The following procedure calculated each coefficient. Firstly, a coefficient $r$ was calculated by the regression line of $1 / Y_{\mathbb{I D x}}$ to $1 / Y_{\mathbb{I D}(x-1)}$ and two coefficients a and $g$ were successively sought by the coefficient and constant of the regression equation of $1 / Y_{10 x}$ and $e^{-r x}$, respectively. In order to have a better match between the regression line and the observation curve, several points in the first few minutes were appropriately deleted. Finally, by comparing the numerical gr of the experimental bait ball and the control bait ball, it is determined which of the 16 stimuli species has an attractive effect on grass carp.

The experiments were carried out twice a day, at 10:00 am and 3:00 pm. At the end of each experiment, the water at the same temperature was changed in the aquarium, and the experimental fish were fed to satiation only once at 4:00 pm daily. Each experiment was repeated at least triplicate times.

\subsection{The Electro-olfactogram (EOG) test}

The electronic olfactory recording test further detected the olfactory responses of grass carp to eight stimuli selected by the behavioral maze test. A capillary glass tube ( $80 \mu \mathrm{m}$ tip diameter) was filled with gelatin ( $8 \% \mathrm{in} 0.6 \% \mathrm{KCl}$ solution). Then the fine platinum wire of the microelectrode (ME- 1 microelectrode with amplifier, Chengdu Taimeng Software Co., Ltd) was inserted into the processed glass capillary to form a microelectrode system according to a previous study (Murphy et al. 2001). Grass carp were held in laboratory tanks supplied with dechlorinated water at (25.0 \pm 0.5$){ }^{\circ} \mathrm{C}$. Larger grass carp (body weight: $40 \pm 0.5 \mathrm{~g}$ ) was chosen because it was too difficult to obtain a recording from the smaller fish as the incurrent pore was too small for the size of electrodes used (Murphy et al. 2001). Immediately before recording, fish were anaesthetized by orally perfusing the gills with dechlorinated tap water containing 3-aminobenzoic acid ethyl ester methanesulfonate (MS-222) (1:8000) (Hill et al. 2002) and an injection of gallamine triethiodide $(0.004 \mathrm{mg} / \mathrm{g} \mathrm{BW})$ into the dorsal muscle, wrapped in a wet towel, and secured to a stand placed in an electrically grounded water bath. Throughout the recording process, a polyethylene tube was used to inject dechlorinated water into the grass carp's mouth to assist its passive breathing. The water bath temperature and the anaesthetic water $\left(25.0 \pm 0.5^{\circ} \mathrm{C}\right)$ during the test approximated that of the holding aquaria to reduce the stress of grass carp. In an attempt to facilitate recording, the overlying skin, cartilage and dorsal aspect of the olfactory sac were removed to expose the olfactory receptor cells. And then, the recording electrode (ME-1 microelectrode with amplifier, Chengdu Taimeng Software Co., Ltd) was placed lightly against, generally perpendicular to the surface of the mucosa, and the reference electrode is clamped on the mouth of the fish. The naris was continuously perfused with dechlorinated tap water to keep the nostrils in a water environment and the stimulating solution was continuously dropped into the dechlorinated tap water injected into the nostril at a rate of $10 \mu \mathrm{L}$ every $10 \mathrm{~s}$. The electrical signal is displayed on the computer through BL-420A biological function experiment system (Chengdu Taimeng Software Co., Ltd). The EOG test system was designed as in Fig. 2. The response was recorded for $5 \mathrm{~s}$ from the odour pulse initiation (Tine and Aleš 2000). Besides, to determine the experiment's accuracy, recording began by determining the olfactory response to $10^{-3} \mathrm{~mol} / \mathrm{L}$ DMPT. If the EOG response to DMPT was normal, testing with stimuli was initiated. If the response was abnormal, the recording electrode and odour tube were repositioned until the normal response was obtained. Each stimulus solution 
was continuously observed more than five similar EOG (amplitude difference $\leq 5 \%$ ), and three grass carp were used in the experiment. Throughout the experiment, when its EOG amplitude changed more than 5\%, the experimental data was discarded (Ma et al. 2003). After the recording was completed, the gills were perfused with tap water until the fish began ventilating, and then fish was put back into its aquarium.

\subsection{The biting-balls test}

The behavioral biting-balls test was used to determine the best attractant concentration of 8 stimuli screened. Sixty young grass carp body weight $(45 \pm 5 \mathrm{~g})$ were held in an aquarium (length, $100 \mathrm{~cm}$; width, $60 \mathrm{~cm}$; height, $60 \mathrm{~cm}$ ) supplied with dechlorinated water for the test. The water depth was kept at $40 \mathrm{~cm}$, and the tank's water temperature was controlled at $(25.0 \pm 0.5){ }^{\circ} \mathrm{C}$ using constant temperature apparatus (Kawabata et al. 1992; Carlberg et al. 2015). The experiments were carried out twice a day, at 10:00 am and 3:00 pm. Stock solutions at the concentration of $1 \times 10^{-1} \mathrm{~mol} / \mathrm{L}$ for each stimulus were prepared, stored at $4{ }^{\circ} \mathrm{C}$. One day before the test, the working solutions at $10^{-2}$ and $10^{-3} \mathrm{~mol} / \mathrm{L}$ were obtained by diluting the stock solution. Three different concentrations of stimuli $(6 \mathrm{ml})$ were added into flour $(10 \mathrm{~g})$ respectively and stirred, and then they were made into bait balls. An $8 \times 8 \mathrm{~cm}^{2}$ mesh then wrapped the bait balls with a mesh size of $0.5 \mathrm{~cm}$ diameter. Bait balls made from distilled water without stimulus were used as a control group. Three experimental balls and a control ball were randomly suspended in the test tank with a distance of $15 \mathrm{~cm}$ apart from each other. Each ball was $20 \mathrm{~cm}$ from the bottom of the fish tank. The number of bites for each bait ball in 6 minutes was recorded with the previously described camera. The optimal concentration of the stimuli was determined by the biting-balls test from the three different concentrations designed.

In order to determine a formula of compound attractants that is the most attractive to grass carp, the $\mathrm{L}_{9}\left(3^{4}\right)$ orthogonal table was used to design the compound stimuli. The biting-balls test was conducted again to determine which combination had the greatest attraction for grass carp. During the test, three randomly selected formulas and a dummy were arranged in a test, and then the three groups with the best performance from each test were further compared. Grass carp were fed with commercial feed at the end of the experiment every afternoon and the fish tank was cleaned and replaced with new water. Each experiment was repeated at least triplicate times.

\subsection{Statistics}

In the behavioral maze test, a Chi-square test (STATISTICA-7.0) was adopted to test the fitness of the estimated series of logistic curve $y=g /\{1+e x p[-$ $r(x-a)]\}$ to the observed one. $P>0.05$ was adopted as the criterion. Besides, one-way ANOVA was used to detect the significance of treatment and then group means were compared using Tukey's multiple range tests to compare the difference among the experimental groups and the control group at the same time point. Data were expressed as mean \pm SE (standard error), and $\mathrm{P}<0.05$ was considered statistically significant. All the data were analyzed with SPSS (Version 19.0, SPSS Inc).

\section{Results}

3.1 Evaluation of repellance and attraction behavior in the maze test

Fig. 3 showed the time-courses of three behaviors in the test of 16 kinds of stimuli and the respective dummy using 30 individuals of grass carp. The number in Fig. 3 indicated the number of each behavior for ten min. Of two systems composed of different stimuli and dummy, the slope ( $r$ ) of the entered time-courses reflects the locomotion activity. The slope of each stimulus can roughly reflect the attraction and avoidance of the stimuli to grass carp. For example, the enter slope of L-lysine decreased obviously in comparison with that of the dummy. It can be judged that L-lysine showed a repellence activity on grass carp. To the opposite, the enter slope of DMPT was roughly bigger than that in the opposite dummy. It can be judged that DMPT showed an attraction behavior on grass carp. Fig. 3 also showed that the number of grass carp staying in the test compartments is small and the gap between them is small, so we will not discuss it. After a long time of observation, the grass carp became active after entering the test area and then left after a short stay. Therefore, the entering or leaving time-courses can best reflect the attraction and repellence effects of various stimuli on grass carp. The cumulative curves of entering or leaving would be analyzed in the following studies. The data in Fig. 3 can be fitted to a logistic curve of time-course represented by $\mathrm{Y}=\mathrm{g} /\{1+\exp [-\mathrm{r}(\mathrm{x}-\mathrm{a})]\}$, where the coefficients, $\mathrm{g}, \mathrm{r}$ and a are constant.

Through a series of calculations on the data in Fig. 3, Table 1 shows the fitness and the coefficients of logistic curves to the two behavioral timecourses as shown in Fig. 3. The chi square value of the entering logic curve is relatively small, which indicates that the time course of grass carp entering the compartments was more consistent with the fitting curve than that of fish leaving. Behaviorally, taking taurine and glycine in Table 2 as an example, grass carp entered the experimental area more times than the control group and showed a certain feeding reaction. Meanwhile, when further multiplying $\mathrm{g}$ by $\mathrm{r}$ of the entering time-course for the two stimuli, the product of $\mathrm{g}$ and $\mathrm{r}$ values of each stimulus was higher than that of the entering time-course in the dummy group (Table 3). This means that the coefficient gr of the entering time-course can be used as a single attractive index for the evaluation of the attractive effect. So we will evaluate the attraction effect of attractants by the entering time-courses using the product of gr. Through a series of calculations on the $\mathrm{g}$ and $\mathrm{r}$ of the entering course in Table 1, Table 3 can be obtained and shows the coefficient values (the product of gr in the entering time-course) of sixteen different substances and the respective dummy. . By comparing the coefficient gr between each stimuli and the dummy, the attractive effect of various kinds of stimuli was obtained.

It can be seen from Table 3, among these 16 stimulating species, DMPT and glycine 
have a strong attractive effect $\left(\mathrm{gr}_{\text {stimulant }} / \mathrm{gr}_{\text {dummy }} \geq 2\right.$ ), and DMT, L-proline, L-alanine, L-arginine, taurine, and L-glutamic acid have an attractive effect on grass carp slightly weaker $\left(1.2<\mathrm{gr}_{\text {stimulant }} / \mathrm{gr}_{\text {dummy }}<2\right)$, while TMAO, L-cysteine, and L-threonine do not affect attracting or inhibiting

$\left(0.8 \leq \mathrm{gr}_{\text {stimulant }} / \mathrm{gr}_{\text {dummy }} \leq 1.2\right)$ on grass carp, and L-methionine, phenylalanine, L-lysine, L-valine, and L-histidine showed inhibitory effects

$\left(0 \leq \mathrm{gr}_{\text {stimulant }} / \mathrm{gr}_{\text {dummy }}<0.8\right)$ on grass carp.

\subsection{Response amplitude of EOG}

The stimulating effect of eight substances selected by the maze experiment on the olfactory sense of grass carp was tested through the microelectrode system. The EOG response of grass carp to the stimuli is a transient biphasic potential change (take taurine as an example, shown in fig. 4). Upon termination of the stimuli of amino acids, the EOG response returns quickly to baseline.

Table 4 shows the EOG response potential amplitude of 8 stimuli to grass carp. At the same time, it can be proved that the substances selected by the maze experiment have a stimulating effect on the smell of grass carp, and it can be seen that the EOG response potential amplitude increases with the concentration of each stimuli. What is interesting is that the sorting of EOG response potential amplitude of the 8 stimuli is inconsistent in each concentration. When the response intensity is $10^{-3} \mathrm{~mol} / \mathrm{L}$, the order of stimuli intensity from low to high was as follows: taurine, L-proline, glycine, DMPT, L-glutamic acid, L-alanine, L-arginine, DMT. When the response intensity is $10^{-2} \mathrm{~mol} / \mathrm{L}$, the order of stimuli intensity from low to high was as follows: taurine, glycine, L-glutamic acid, L-proline, L-arginine, DMPT, L-alanine, DMT. When the response intensity is $10^{-1} \mathrm{~mol} / \mathrm{L}$, the order of stimuli intensity from low to high was as follows: taurine, L-glutamic acid, L-proline, L-arginine, glycine, L-alanine, DMPT, DMT.

\subsection{The biting-balls test}

For each substance, three experimental groups (concentrations) and a dummy group were set to choose the optimal concentration by comparing the biting times. It can be seen from Fig. 5 that the biting times of the eight substances selected in the maze test showed different degrees of attraction and repulsion to grass carp. Generally, the biting frequency of DMPT, DMT, glycine, L-arginine, L-glutamic acid, and L-alanine was significantly higher than that of the dummy group, and grass carp showed a strong desire to eat these bait balls. In contrast, L-proline showed food rejection, while taurine showed no significant effect on grass carp. Specifically, at $10^{-1} \mathrm{~mol} / \mathrm{L}$, the number of biting times of DMT is significantly higher than that of the other three concentrations. The biting times of glycine, L-glutamic acid and L-arginine at $10^{-2} \mathrm{~mol} / \mathrm{L}$ are significantly different from that of the control group.

Taking into account the cost issues such as the price and addition amount of stimuli, four substances, DMT, glycine, L-glutamic acid and glycine, were selected for further investigation of the attractive effect of their compounds. The best concentration determined and two more concentrations which were half or twice of the optimal attractant concentration, respectively, of each stimulus were set, and the $L_{9}\left(3^{4}\right)$ orthogonal table was used to design 9 formulas (Table 5) for further comparing the number of biting times.

Fig. 6 showed that formulas 2, 5, and 9 have the highest number of pecks, all of which are significantly different from the control group. When comparing formula 2, 5 and 9, formula 9 is the most attractive to grass carp (Fig. 6).

\section{Discussion}

The fishing bait needs to be based on an odour source that releases feeding attractants that elicit the food search behavior of the target species (Løkkeborg et al. 2014). The olfactory system of fish can receive signals from a long distance, which makes it very important to obtain information about food supply and existence and to choose the most suitable search direction (Kasumyan 2004). Most fish completely lose their foraging performance after losing their sense of smell and cannot find the odour source even at high concentrations of food substances (Hara 1975; Kasumyan 1997). In contrast, the taste system determines whether the fish will accept the food (Ishida and Kobayashi 1992; Kasumyan and Sidorov 2012). Based on these theories, this is the first study to explore the substances that may stimulate grass carp's sense of smell (do not exclude other systems that play a role in foraging behavior) by the behavioral maze test and EOG test. The maze test results showed that DMPT and glycine have a strong attractive effect on grass carp. DMT, L-proline, L-alanine, L-arginine, taurine, and L-glutamic acid have a slightly weaker attractive effect on grass carp. At the same time, TMAO, L-cysteine and L-threonine do not affect (attract or repel) grass carp, and L-methionine, phenylalanine, L-lysine, Lvaline, and L-histidine even showed inhibitory effects on grass carp (Table 3). The results indicating that there were significant differences in the attractiveness of different substances to grass carp. This is consistent with the conclusions of other fish studies (Harada et al. 1988; Harada and Miyasaki 1993; Harada et al. 1995). An interesting phenomenon was discovered in the labyrinth experiment. For example, DMPT, DMT, L-proline, glycine and L-alanine has an obvious attraction for grass carp, after entering the test area, the grass carp slowly enter the bottom of the test compatment and gather at the bottom, showing obvious feeding behaviors such as pecking at the glass wall. This phenomenon is the same as that of the experiment by Harada et who investigated the attraction effect of sugars to the yellowtail (Seriola lalandi) (Harada et al. 1995). The behavioral biting-ball test also showed that these substances can stimulate the feeding response of grass carp. The attractive olfactory effect of these substances on fish has also been reported in other fish species.

Nakajima found that DMPT has a strong attraction to carp (Cyprinus carpio) (Kenji et al. 1989). L-alanine has a significant effect on carp attraction and exploration (Saglio et al. 1990). It has also been proven that glycine has an attractant effect on the crucian carp (Carassius auratus auratus) (Wu et al. 199). This may also explain that the bait of grass carp added with DMPT and glycine also attract the most common carp and crucian carp in 
Chinese waters (personal observations during fishing). The results of the present study showed that arginine could attract grass carp, but Kasumyan found that L-arginine can repel common carp (Kasumyan and Morsi 1996). This result also has theoretical support for the production of special grass carp bait. For example, in Wuhan, China, the citizens like grass carp but not common carp. The bait of grass carp added with L-arginine can repel the common carp, reduce their chance of hooking, thus to focus on grass carp fishing.

The results of EOG test confirmed the stimulating effect of eight substances screened by the behavioral maze test on grass carp olfactory. All of the eight substances had different degrees of stimulation on the olfactory function of grass carp. In terms of the waveform, the olfactory response of the grass carp recorded in this experiment is a transient biphasic potential change (Fig. 4). The waveform of this experiment is the same as that of gibel carp (Carassius auratus gibelio) to amino acids (Zhao 2007). In contrast, the EOG responses recorded during electrophysiological studies on channel catfish (Ictalurus punctatus), white catfish (Ictaluru catus), sea catfish (Arius felis) are all transient single-phase negative potentials (Caprio 1980; Yamada and Nakatani 2001). It is also worth noting that Johnsen et al used a calomel electrode and a Grass P-18 preamplifier to study the EOG response of grass carp to amino acids and the recorded waveform was single-phase wave, and the unit of amplitude was mV (Johnsen et al. 1988), which was different from our experimental results. The reason may be that different electrodes can be used to obtain EOG signals and the characteristic of these signals change depending on the structure and placement of the electrodes (López et al. 2016). The ME-1 microelectrode amplifier produced by Taimeng company is used in this experiment, ME-1 microelectrode amplifier is composed of electrode and amplifier. It has a simple structure and limited amplification. This leads to different units of EOG response amplitude of grass carp. On the other hand, the EOG signal is the result of many individual receptor cell currents producing a recordable voltage drop over the extracellular pathway completed through the mucus and water (Getchell 1974). The relative position of the recording and reference electrodes, their internal resistance and the conductivity of the water flowing over the epithelium will affect the signal amplitude the relative position of the recording and reference electrodes, their internal resistance and the conductivity of the water flowing over the epithelium will affect the signal amplitude (Zhao 2007).

In the present study, the EOG response amplitude of 8 kinds of stimuli was different at the same concentration. It should be pointed out that in terms of the response amplitude of EOG, the order of stimuli at $10^{-3} \mathrm{~mol} / \mathrm{L}$ concentration are L-arginine $>$ L-alanine $>\mathrm{L}$-glutamic acid $>$ glycine $>\mathrm{L}$-proline $(T a b l e$ 4). The results support the conclusion of a previous study on grass carp olfaction (Johnsen et al. 1988). Previous studies have shown that among the 19 amino acid stimuli at the tested concentrations, L-alanine all had the strongest response to the rabbitfish (Siganus fuscescens Houttuyn) (Ishida and Kobayashi 1992), and young yellowtail (Kohbara et al. 2000). But, under the stimuli of $10^{-3} \mathrm{~mol} / \mathrm{L}$ amino acids, L-lysine had the largest response to carp (Goh and Tamura 1978). In this experiment, the response amplitude of grass carp to DMT was the largest at the three different concentrations. It can be concluded that although the response of fish to amino acids in fish olfactory electrophysiological experiments is not species-specific, the response intensity of different fish species to different amino acids varies greatly.

In this study, the response of grass carp to DMT, L-arginine, L-glutamic acid and glycine in general was strong. The biting-ball test results showed that the behavior of grass carp to DMT was the strongest in this experiment, which was the same as that of the olfactory electrophysiology experiment. It can be concluded that DMT is an effective attractive monomer for grass carp. However, it should be noted that the results of biting behavioral responses induced by stimulus were not completely the same as those of olfactory electrophysiology. Our results showed that L-arginine had a great effect on the olfactory function of grass carp and stimulated the biting response at higher concentrations. However, L-Arginine at a concentration of $10^{-3} \mathrm{~mol} / \mathrm{L}$ has a strong response in electrophysiological experiments but showed a slight inhibitory effect on the feeding of grass carp in the behavioral biting-balls test. The same phenomenon was found in the experiment of crucian carp (Zhao 2007), which indicated that the olfactory electricity experiment could not totally distinguish the substances that could attract fish.

In the biting-balls test, grass carp eats small pieces of dough into the mouth. This process is a comprehensive function of smell and taste and other sensory systems. The taste system plays a major role in this process because evaluation by fish of taste characteristics of the food and its agreement with the food requirements significantly depends on the functioning of the taste system (Chaudhari et al. 2009). The biting frequency of DMPT, DMT, glycine, L-arginine, L-glutamic acid and L-alanine was significantly higher than that of the dummy group, and grass carp showed a strong desire to eat the bait. But L-proline showed food rejection, and taurine showed no significant difference (Fig. 5). The behavioral biting responses of the eight substances screened by the maze test were not completely consistent with those of the maze test, which all had an attractive effect on grass carp. This may be the fact that the feeding mechanism of grass carp is affected by olfactory, gustatory and other sensory mechanisms. As a result, Lproline and taurine are not effective to improve swallowing. In fact, it was found that L-proline could attract grass carp's sense of smell (Table 3 ), but when grass carp really ate it, it showed a repellant response. Similarly, Kasumyan reported that the oral taste system of grass carp rejected L-proline and that glycine and arginine promote food intake (Kasumyan and DÖving 2003). This is consistent with our experimental results. Interestingly, he also found that L-cysteine can promote feeding activity in the oral gustatory system of grass carp, but we removed this substance because it cannot attract the smell of grass carp in the maze test (Table 3).

The orthogonal experiment showed that formula 9 containing DMT, glycine, glutamic acid and L-arginine showed stronger phagocytosis than the control group and other formulas. In the experimental video, it was observed that grass carp kept not only biting at the bait ball containing these stimuli, but also shaking their head to tear off small pieces of dough after biting it. In the actual fishing, the author used the bait added with formula 9 and achieved to catch many grass carp of different sizes, in association with crucian carp and common carp.

To conclude, this study combined behavioral and physiological tests to systematically elaborate the feeding promoting effects of 16 kinds of stimuli that can promote the feeding activityof different kinds of fish on grass carp, and finally came to a formula that can stimulate the smell and taste 
systems of grass carp and promote the feeding of grass carp. With the rise of the leisure fishing industry, the special attractant for grass carp can provide fishing fun for anglers and it also has good economic prospects.

\section{Declarations}

\section{Author Declarations}

\section{Funding}

This study was financially supported by the National Key R\&D Program of China (2019YFD0900200).

\section{Conflicts of interest}

The authors have no financial or proprietary interests in any material discussed in this article.

\section{Availability of data and material}

The datasets generated during and/or analysed during the current study are available from the corresponding author on reasonable request.

\section{Code availability}

Not applicable

\section{Author contributions}

All authors contributed to the study conception and design. Material preparation, data collection and analysis were performed by Haojie Yu, Xiaoyu Wang, Fanshuang Kong and Qingsong Tan. The first draft of the manuscript was written by Haojie Yu and all authors commented on previous versions of the manuscript. All authors read and approved the final manuscript.

\section{Ethics approval}

With the submission of this manuscript, I would like to confirm that the above-mentioned manuscript has not been published elsewhere, accepted for publication elsewhere or under editorial review for publication elsewhere; and that my Institute's Key Laboratory of Freshwater Animal Breeding, Ministry of Agriculture of China / Hubei Provincial Engineering Laboratory for Pond Aquaculture/College of Fisheries, Huazhong Agricultural University, Wuhan 430070, China representative is fully aware of this submission.

All procedures were approved by the Institutional Animal Care and use Committee (IACUC) of Huazhong Agricultural University (Wuhan, China) for laboratory animal use. Culturing of fish was performed according to the common Organization for Economic Cooperation and Development (OECD) protocol for fishes.

\section{Consent to participate}

agree

\section{Consent for publication}

agree

\section{Acknowledgments}

This study was financially supported by the National Key R\&D Program of China (2019YFD0900200).

\section{References}

Caprio J (1980) Similarity of olfactory receptor responses (EOG) of freshwater and marine catfish to amino acids. Can J Zool 58:1778-1784. https://doi.org/10.1139/z80-245

Carlberg H, Cheng K, Lundh T, Brnns E (2015) Using self-selection to evaluate the acceptance of a new diet formulation by farmed fish. Appl Anim Behav Sci 171:226-232. https://doi.org/10.1016/j.applanim.2015.08.016

Chaudhari N, Pereira E, Roper S D (2009) Taste receptors for umami: the case for multiple receptors. Am J Clin Nutr 90:738S-742S.

https://doi.org/10.3945/ajcn.2009.27462H

Franklyn A, Wang Y, Yu N, Wang J, Le Q (2017) Transcriptome analysis reveals L-amino acids as olfactory stimulant in the large yellow croaker (Larimichthys crocea). J Aquac Res Dev 8:2. https://doi.org/10.4172/2155-9546.1000475

Page 7/17 
Getchell T V (1974) Electrogenic sources of slow voltage transients recorded from frog olfactory epithelium. J Neurophysiol 37:1115-1130. https://doi.org//10.1152/jn.1974.37.6.1115

Goh Y, Tamura T (1978) The electrical responses of the olfactory tract to amino acids in carp. J Aquac Res Dev 44:341-344. https://doi.org/10.2331/suisan.44.341

Hara T J (1975) Olfaction in fish. Prog Neurobiol 5:271-335. https://doi.org/10.1016/0301-0082(75)90014-3

Hara T J (1994) The diversity of chemical stimulation in fish olfaction and gustation. Rev Fish Biol Fish 4:1-35. https://doi.org/10.1007/BF00043259

Hara T J (2010) Feeding behaviour in some teleosts is triggered by single amino acids primarily through olfaction. J Fish Biol 68:810-825. https://doi.org/10.1111/j.0022-1112.2006.00967.x

Harada K (1982) The attractive effect of food based on the behavioral responses of juvenile yellowtail Seriola quinqueradiata. Nippon Suisan Gakkai Shi 48:1047-1054. https://doi.org/10.2331/suisan.48.1047

Harada K, Abe Y, Sugiyama T (1988) Activities of carboxylic acids and acidic amino acids as repellents in the oriental weatherfish Misgurnus anguillicaudatus. Nippon Suisan Gakkai Shi 54:2135-2138. https://doi.org/10.2331/suisan.54.2135

Harada K, Miyasaki T (1993) Attraction activities of fruit extracts for the oriental weather-fish Misgurnus anguillicaudatus. Nippon Suisan Gakkai Shi 59:1757-1762. https://doi.org/10.2331/suisan.59.1757

Harada K, Miyasaki T, Tamura Y (1995) Attraction of yellowtail, Seriola quinqueradiata for sugars and related compounds. Suisan Zoshoku 43:51-55. https://doi.org/10.11233/aquaculturesci1953.43.51

Hill J V, Davison W, Forster M E (2002) The effects of fish anaesthetics (MS222, metomidate and AQUI-S) on heart ventricle, the cardiac vagus and branchial vessels from Chinook salmon ( Oncorhynchus tshawytscha ). Fish Physiol Biochem 27:19-28(2002).

https://doi.org/10.1023/B:FISH.0000021742.30567.2d

Hu J, Le Q, Zhang M, Kuang S, Gu W, Sun Y, Jean Jacques K, Zhang Y, Li Y, Sun J (2021) Effects of amino acids on olfactory-related receptors regulating appetite in silver pomfret. Aquac Res:(2021). https://doi.org/10.1111/are.15102

Ishida Y, Kobayashi H (1992) Stimulatory effectiveness of amino acids on the olfactory response in an algivorous marine teleost, the rabbitfish Siganus fuscescens Houttuyn. J Fish Biol 41:737-748. https://doi.org/10.1111/j.1095-8649.1992.tb02703.x

Jiesheng K, John C (1991) Electro-olfactogram and multiunit olfactory receptor responses to binary and trinary mixtures of amino acids in the channel catfish, Ictalurus punctatus. J Gen Physiol 98:699-721. https://doi.org/10.1085/jgp.98.4.699

Johnsen P, Zhou H, Adams M (1988) Olfactory sensitivity of the herbivorous grass carp, Ctenopharyngodon idella, to amino acids. J Fish Biol 33:127134. https://doi.org/10.1111/j.1095-8649.1988.tb05454.x

Kasumyan A (1997) Gustatory reception and feeding behavior in fish. Journal of Ichthyology 37:72-86.

Kasumyan A (2004) The olfactory system in fish: structure, function, and role in behavior. J Ichthyol 44:S180.

Kasumyan A, Mikhailova E (2017) Palatability of stereoisomers and other amino acid derivatives to fish. J Evol Biochem Physiol 53:317-323. https://doi.org/10.1134/S0022093017040081

Kasumyan A, Morsi A K (1996) Taste sensitivity of common carp Cyprinus carpio to free amino acids and classical taste substances. Journal of Ichthyology 36:391-403.

Kasumyan A, Sidorov S (2012) Effects of the long-term anosmia combined with vision deprivation on the taste sensitivity and feeding behavior of the rainbow trout Parasalmo (= Oncorhynchus) mykiss. J Ichthyol 52:109-119. https://doi.org/10.1134/S0032945212010079

Kasumyan A O, DÖving K B (2003) Taste preferences in fishes. Fish Fish (Oxf) 4:289-347. https://doi.org/10.1046/j.1467-2979.2003.00121.x

Kawabata K, Sudo S, Tsubaki K, Tazaki T, Ikeda S (1992) Effects of Amino Acids on Pecking Behavior of the Rose Bitterling Rhodeus ocellatus ocellatus. Nsugaf 58:833-838. https://doi.org/10.2331/suisan.58.833

Kenji N, Aritsune U, Yuzaburo I (1989) A new feeding attractant, dimethyl-. BETA.-propiothetin, for freshwater fish. Nippon Suisan Gakkai Shi 55:689695. https://doi.org/10.2331/suisan.55.689

Kohbara J, Hidaka I, Morishita T, Miyajima T (2000) Gustatory and olfactory sensitivity to extracts of jack mackerel muscle in young yellowtail Seriola quinqueradiata. Aquaculture 181:127-140. https://doi.org/10.1016/S0044-8486(99)00222-7

Page 8/17 
Lim L-S, Lai J S-K, Yong A S-K, Shapawi R, Kawamura G (2015) A preliminary study on the taste preferences of marble goby (Oxyeleotris marmoratus) for amino acids. Songklanakarin J Sci Technol 37:397-400.

Løkkeborg S, Johannessen T (1992) The importance of chemical stimuli in bait fishing-fishing trials with presoaked bait. Fish Sci 14:21-29. https://doi.org/10.1016/0165-7836(92)90070-A

Løkkeborg S, Siikavuopio S I, Humborstad O-B, Utne-Palm A C, Ferter K (2014) Towards more efficient longline fisheries: fish feeding behaviour, bait characteristics and development of alternative baits. Rev Fish Biol Fish 24:985-1003. https://doi.org/10.1007/s11160-014-9360-z

López A, Ferrero F, Valledor M, Campo J C, Postolache O, 2016. A study on electrode placement in EOG systems for medical applications, 2016 IEEE International Symposium on Medical Measurements and Applications (MeMeA), IEEE, pp. 1-5. https://doi.org/10.1109/MeMeA.2016.7533703

Ma X L, Hong W S, Chai M J, Pan L A, Hung H Y, Zhang Q Y (2003) Comparison of olfactory responses of snakehead fish Channa argus to sex pheromones. Xiamen Da Xue Xue Bao Zi Ran Ke Xue Ban 42:781-786. https://doi.org/10.3321/j.issn:0438-0479.2003.06.022

Miyasaki T, Harada K, Maeda H (1999) Statistical estimation of probable feeding attractive amino acids for abalone in vegetable extracts. Suisan Zoshoku 47:455-456. https://doi.org/10.11233/aquaculturesci1953.47.455

Murphy C A, Stacey N E, Corkum L D (2001) Putative Steroidal Pheromones in the Round Goby, Neogobius melanostomus: Olfactory and Behavioral Responses. J Chem Ecol 27:443-470. https://doi.org/10.1023/A:1010376503197

Olsén K H, Sukovich N, Backman J, Lundh T (2018) Chemical foraging stimulation in the omnivorous species crucian carp, Carassius carassius (Linnaeus 1758). Aquac Rep 12:36-42. https://doi.org/10.1016/j.aqrep.2018.09.003

Ozorio R O A, Hubbard P C, Barata E N, Valente L M P, Canário A V M (2010) Olfactory Sensitivity to amino acids in the blackspot seabream (Pagellus Bogaraveo, Brünnich 1768): How effective is the electro-olfactogram in seawater? Eur Aquac Soc:946-947. https://doi.org/10.1007/s00359-011-06465

Saglio P, Fauconneau B, Blanc J (1990) Orientation of carp, Cyprinm carpio L., to free amino acids from Tubifex extract in an olfactometer. J Fish Biol 37:887-898. https://doi.org/10.1111/j.1095-8649.1990.tb03592.x

Tine V, Aleš K (2000) Coding principles in fish olfaction as revealed by single unit, EOG and behavioral studies. Pflugers Arch 439:R193-R195. https://doi.org/10.1007/s004240000142

Wu Y, Bao H, Wu W, Fang W (199) Feeding attraction activties of amino acids for crucian carp(Carassius auratus auratus) and loach(Misgurnus anguillicaudatus). Shuichan Xuebao(in Chinese with English abstract) 17:337-339. https://doi.org/CNKI:SUN:SCKX.0.1993-04-010

Yamada H, Nakatani K (2001) Odorant-induced Hyperpolarization and Suppression of cAMP-activated Current in Newt Olfactory Receptor Neurons. Chem Senses 26:25-34. https://doi.org/doi.org/10.1093/chemse/26.1.25

Zhang H M, Xia M S, Cai-Hong HU (2005) Preliminary study on feeding attraction activities of TMAO for Penaeus vanname. Journal of Northwest SciTech University of Agriculture and Forestry. https://doi.org/10.1360/biodiv.050121

Zhao H Y (2007) Studies on feeding stimulants for gibel carp (Carassius auratus gibelio). Doctoral Dissertation,Institute of Hydrobiology, Chinese Academy of Sciences(in Chinese with English abstract).

Zou Q, Huang Y, Cao J, Zhao H, Wang G, Li Y, Pan Q (2017) Effects of four feeding stimulants in high plant-based diets on feed intake, growth performance, serum biochemical parameters, digestive enzyme activities and appetite-related genes expression of juvenile GIFT tilapia (Oreochromis sp.). Aquac Nutr 23:1076-1085. https://doi.org/10.1111/anu.12475

\section{Tables}




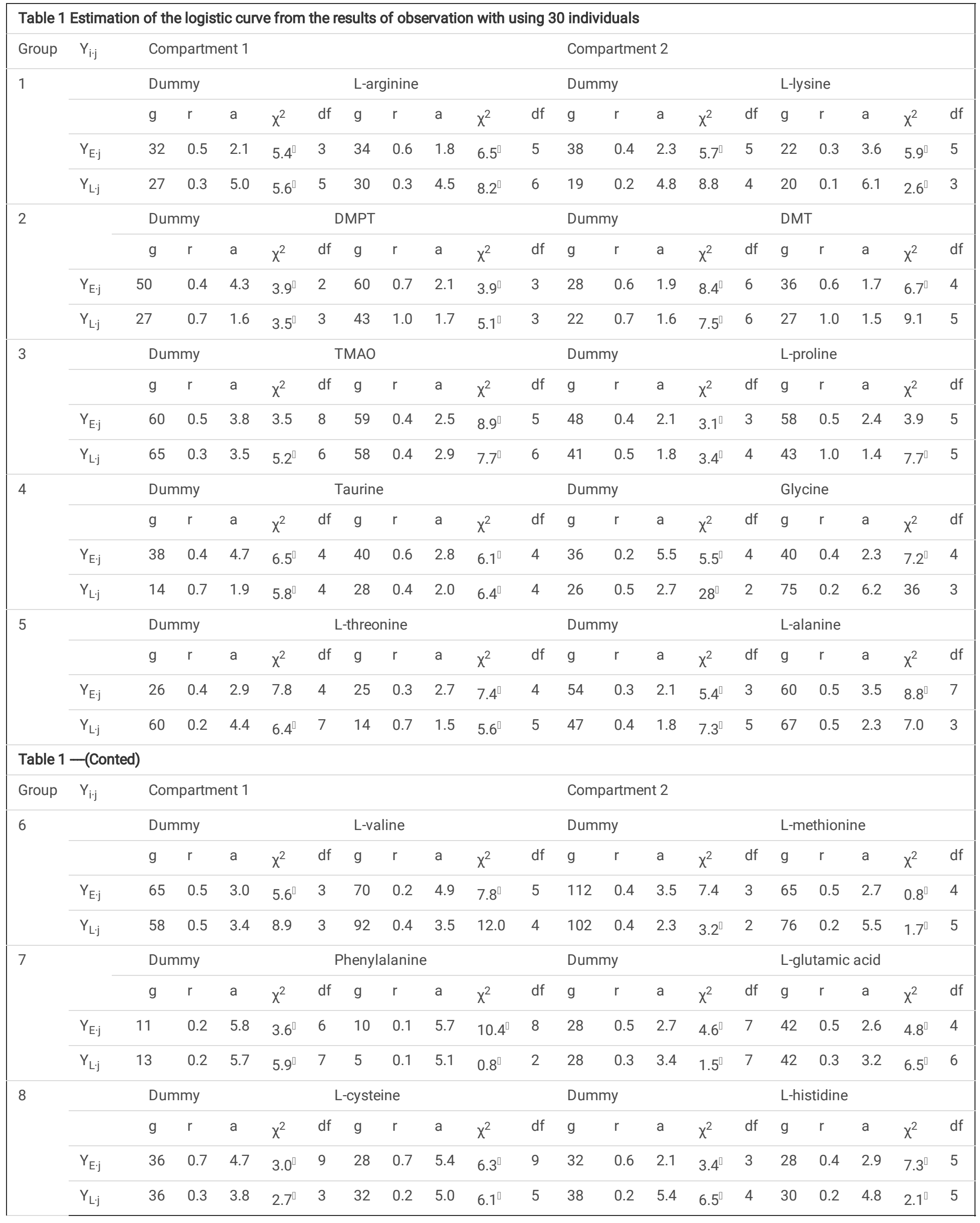

${ }^{\square} \mathrm{P}\left(\mathrm{X}^{2} \llbracket \mathrm{X}^{2}{ }_{0.05}\right) \llbracket 0.05$ 
The $Y_{E \cdot X}$ and $Y_{L \cdot X}$ show the number of grass carp which entered and left in the test compartment respectively.

r, estimated from the coefficients of the regression of $Y_{1 \cdot x}$ on reciprocal of $Y_{1 \cdot(x-1)}$.

a and $r$, estimated from the coefficient and constant of the regression line of reciprocal of $Y_{1 \cdot x}$ on $\exp (-r x)$.

Table 2 General evaluation of the eight kinds of stimuli as grass carp attractants through the observations of exploratory and feeding

\begin{tabular}{|llll|}
\hline Stimuli & Behavior & \multicolumn{2}{c|}{ General evaluation } \\
\cline { 2 - 3 } & Entering times & Exploratory and feeding & \\
\hline Dummy & little & none & none \\
\hline Taurine & strong & Strong and ceaseless & high \\
\hline Dummy & little & none & none \\
\hline Glycine & moderate & Strong & moderate \\
\hline
\end{tabular}

Table 3 The attractive effect of various kinds of stimuli on grass carp

\begin{tabular}{|c|c|c|c|c|c|}
\hline NO. & & Attractive index $\left(\mathrm{gr}^{\sqrt{ }}\right)$ & NO. & & $\begin{array}{l}\text { Attractive index } \\
\left(\mathrm{gr}^{\sqrt{ }}\right)\end{array}$ \\
\hline \multirow[t]{2}{*}{1} & Dummy & $16^{\square}$ & \multirow[t]{2}{*}{9} & Dummy & 10 \\
\hline & L-arginine & $20^{\square}$ & & L-threonine & $8^{\square}$ \\
\hline \multirow[t]{2}{*}{2} & Dummy & $15^{\square}$ & \multirow[t]{2}{*}{10} & Dummy & $16^{\square}$ \\
\hline & L-lysine & $7^{\square}$ & & L-alanine & $30^{\square}$ \\
\hline \multirow[b]{2}{*}{3} & Dummy & $20^{\square}$ & \multirow[b]{2}{*}{11} & Dummy & $33^{\square}$ \\
\hline & DMPT & $42^{\square}$ & & L-valine & $14^{\square}$ \\
\hline \multirow[t]{2}{*}{4} & Dummy & $17^{\square}$ & \multirow[t]{2}{*}{12} & Dummy & 45 \\
\hline & DMT & $22^{\square}$ & & L-methionine & $33^{\square}$ \\
\hline \multirow[b]{2}{*}{5} & Dummy & $30^{\square}$ & \multirow[t]{2}{*}{13} & Dummy & $2^{\square}$ \\
\hline & TMAO & $24^{\square}$ & & Phenylalanine & $1^{\square}$ \\
\hline \multirow[t]{2}{*}{6} & Dummy & $19^{\square}$ & \multirow[t]{2}{*}{14} & Dummy & $14^{\square}$ \\
\hline & L-proline & $29^{\square}$ & & L-glutamic acid & $21^{\square}$ \\
\hline \multirow[t]{2}{*}{7} & Dummy & $15^{\square}$ & \multirow[t]{2}{*}{15} & Dummy & $25^{\square}$ \\
\hline & Taurine & $24^{\square}$ & & L-cysteine & $20^{\square}$ \\
\hline \multirow[t]{2}{*}{8} & Dummy & $7^{\square}$ & \multirow[t]{2}{*}{16} & Dummy & $19^{\square}$ \\
\hline & Glycine & $16^{\square}$ & & L-histidine & $11^{\square}$ \\
\hline
\end{tabular}

${ }^{\square} \mathrm{P}\left(\mathrm{X}^{2} \otimes \mathrm{X}^{2}{ }_{0.05}\right) \otimes 0.05$

The $g$ and $r$ of attraction index (A.I.gr in abbreviation) are derived from the coefficient of a logistic curve $Y=g /\{1+e x p[-r(x-a)]\}$ being applied to entering time-course for grass carp.

Table 4 The comparison of EOG responses of grass carp to eight kinds of stimuli at different concentration $(\mu \mathrm{V})$ 


\begin{tabular}{|llll|}
\hline Stimuli & $10^{-3} \mathrm{~mol} / \mathrm{L}$ & $10^{-2} \mathrm{~mol} / \mathrm{L}$ & $10^{-1} \mathrm{~mol} / \mathrm{L}$ \\
\hline L-alanine & $117.7 \pm 6.2 \mathrm{Ac}$ & $457.9 \pm 19.2 \mathrm{Bd}$ & $567.0 \pm 15.6 \mathrm{Cde}$ \\
\hline Taurine & $49.3 \pm 2.9 \mathrm{Aa}$ & $80.2 \pm 2.7 \mathrm{Ba}$ & $161.9 \pm 5.6 \mathrm{Ca}$ \\
\hline L-proline & $62.4 \pm 1.8 \mathrm{Aab}$ & $252.0 \pm 8.0 \mathrm{Bb}$ & $380.9 \pm 15.0 \mathrm{Cb}$ \\
\hline Glycine & $85.1 \pm 6.9 \mathrm{Aabc}$ & $226.3 \pm 13.3 \mathrm{Bb}$ & $485.5 \pm 15.8 \mathrm{Ccd}$ \\
\hline DMPT & $94.6 \pm 9.2 \mathrm{Abc}$ & $455.1 \pm 17.9 \mathrm{Bd}$ & $612.1 \pm 18.4 \mathrm{Cef}$ \\
\hline DMT & $231.7 \pm 16.2 \mathrm{Ae}$ & $573.7 \pm 8.5 \mathrm{Be}$ & $659.9 \pm 20.4 \mathrm{Cf}$ \\
\hline L-glutamic acid & $105.6 \pm 10.3 \mathrm{Ac}$ & $227.9 \pm 17.9 \mathrm{Bb}$ & $347.7 \pm 25.9 \mathrm{Cb}$ \\
\hline L-arginine & $166.2 \pm 8.9 \mathrm{Ad}$ & $346.7 \pm 19.4 \mathrm{Bc}$ & $416.1 \pm 21.0 \mathrm{Bbc}$ \\
\hline
\end{tabular}

All data were expressed as means \pm SE $(n=3)$. Different lowercase letters after the same column data indicate a significant difference between different stimuli $(P<0.05)$. Different capital letters after the data in the same row indicate significant difference between different concentration of each stimulus $(P<0.05)$.

Table 5 Orthogonal test schemes

\begin{tabular}{|lllll|}
\hline Formula & $\begin{array}{l}\text { DMT } \\
(\mathrm{mol} / \mathrm{L})\end{array}$ & Glycine $(\mathrm{mol} / \mathrm{L})$ & L-glutamic acid $(\mathrm{mol} / \mathrm{L})$ & L-arginine $(\mathrm{mol} / \mathrm{L})$ \\
\hline 1 & $2 \times 10^{-1}$ & $2 \times 10^{-2}$ & $2 \times 10^{-2}$ & $2 \times 10^{-2}$ \\
\hline 2 & $2 \times 10^{-1}$ & $1 \times 10^{-2}$ & $1 \times 10^{-2}$ & $1 \times 10^{-2}$ \\
\hline 3 & $2 \times 10^{-1}$ & $5 \times 10^{-3}$ & $5 \times 10^{-3}$ & $5 \times 10^{-3}$ \\
\hline 4 & $1 \times 10^{-1}$ & $2 \times 10^{-2}$ & $1 \times 10^{-2}$ & $5 \times 10^{-3}$ \\
\hline 5 & $1 \times 10^{-1}$ & $1 \times 10^{-2}$ & $5 \times 10^{-3}$ & $2 \times 10^{-2}$ \\
\hline 6 & $1 \times 10^{-1}$ & $5 \times 10^{-3}$ & $2 \times 10^{-2}$ & $1 \times 10^{-2}$ \\
\hline 7 & $5 \times 10^{-2}$ & $2 \times 10^{-2}$ & $5 \times 10^{-3}$ & $1 \times 10^{-2}$ \\
\hline 8 & $5 \times 10^{-2}$ & $1 \times 10^{-2}$ & $2 \times 10^{-2}$ & $5 \times 10^{-3}$ \\
\hline 9 & $5 \times 10^{-2}$ & $5 \times 10^{-3}$ & $1 \times 10^{-2}$ & $2 \times 10^{-2}$ \\
\hline
\end{tabular}

\section{Figures}




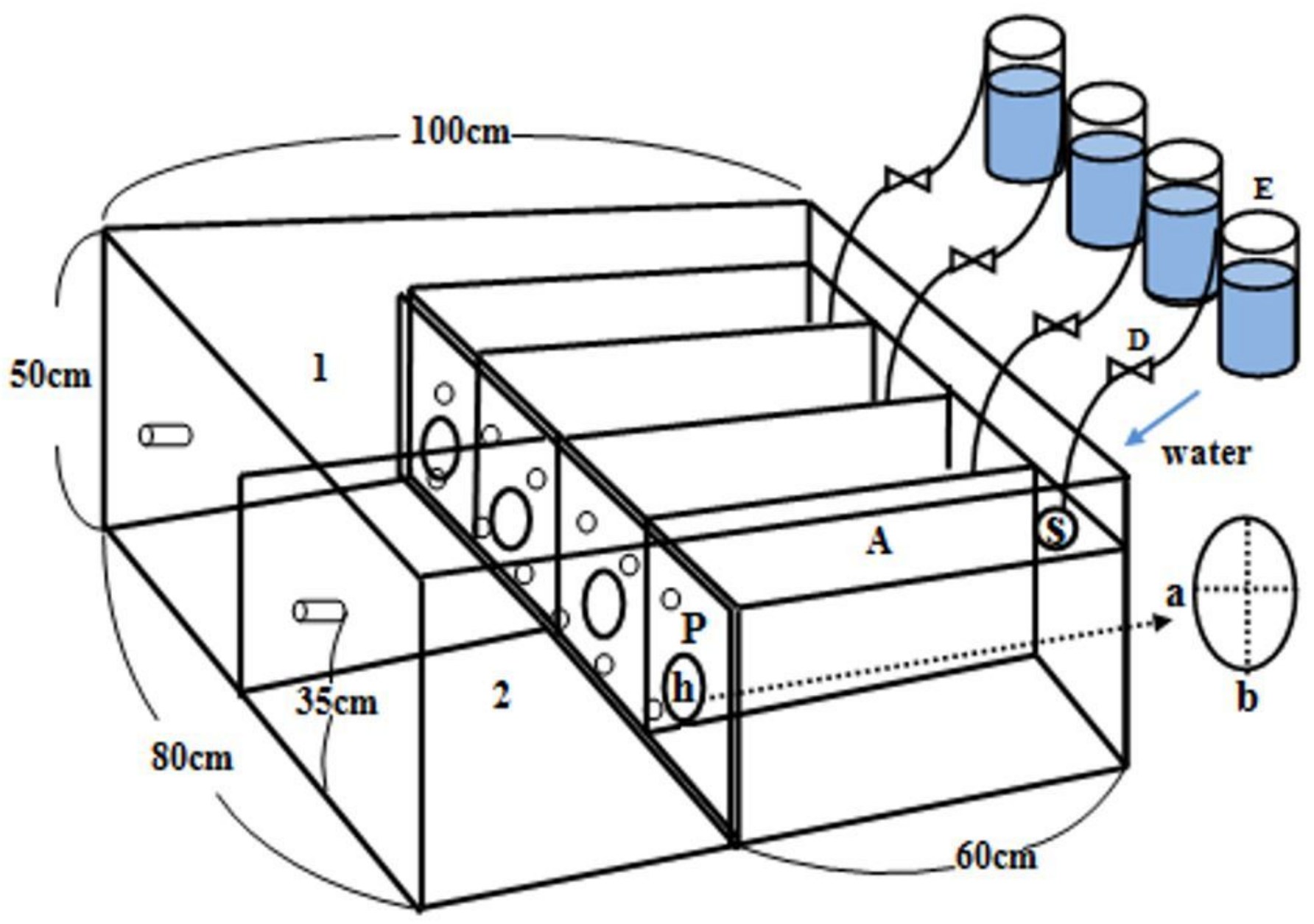

Figure 1

The test aquarium designed in the study. 1 and 2, resident compartments; $A$, test compartments; $D$, the water regulating valve; $E$, water storage bucket; $h$, elliptical holes $(a=5 \mathrm{~cm}, b=8 \mathrm{~cm})$; P, partition; $S$, the position of gauze ball containing test sample or dummy (control); 


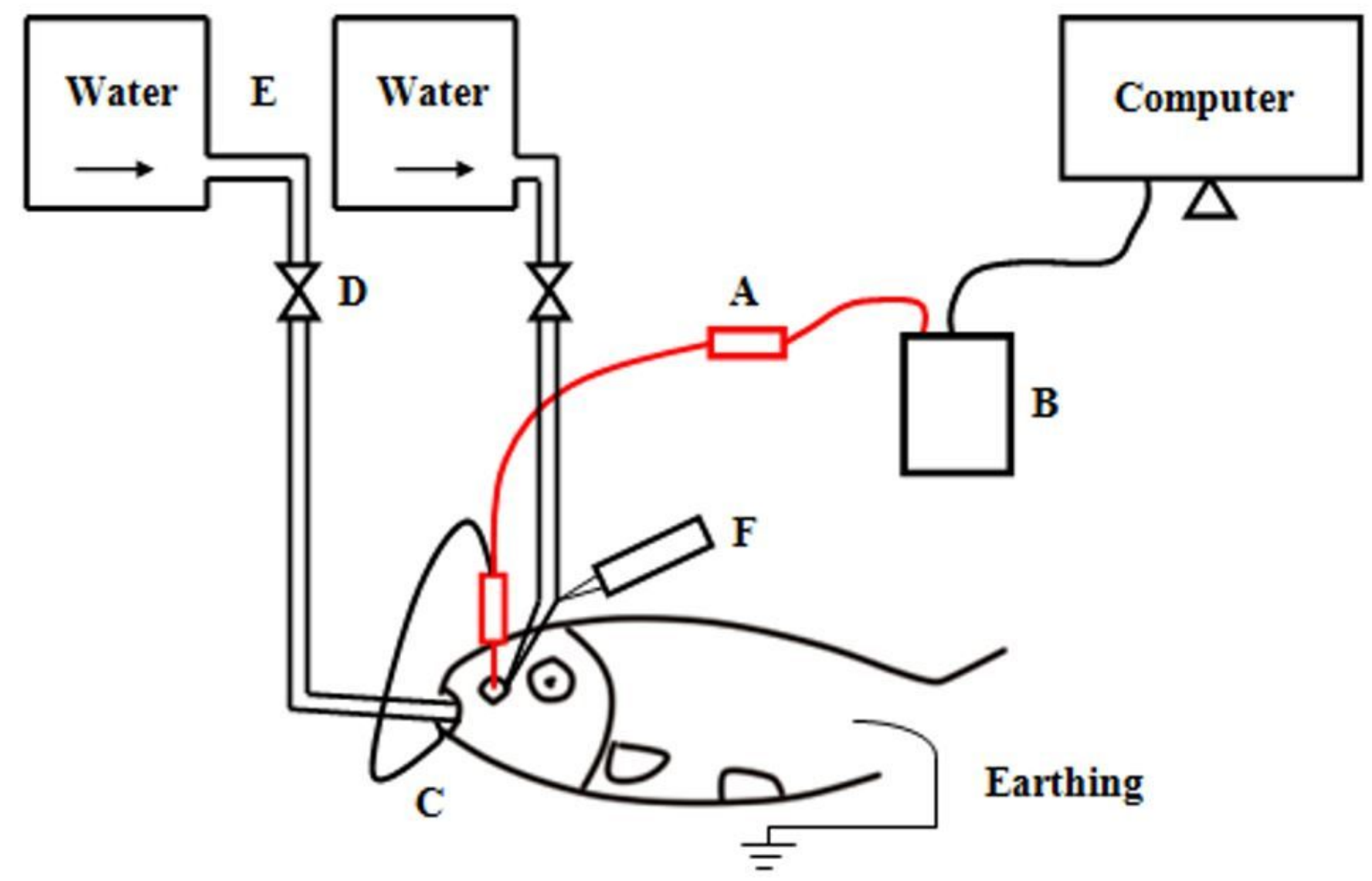

Figure 2

The electro-olfactogram (EOG) test system designed in the study. A, ME-1 microelectrode amplifier; B, BL-420A biological function experiment system; $\mathrm{C}$, reference electrode; $\mathrm{D}$, The water regulating valve; $\mathrm{E}$, Water storage bucket; F, stimuli injection 


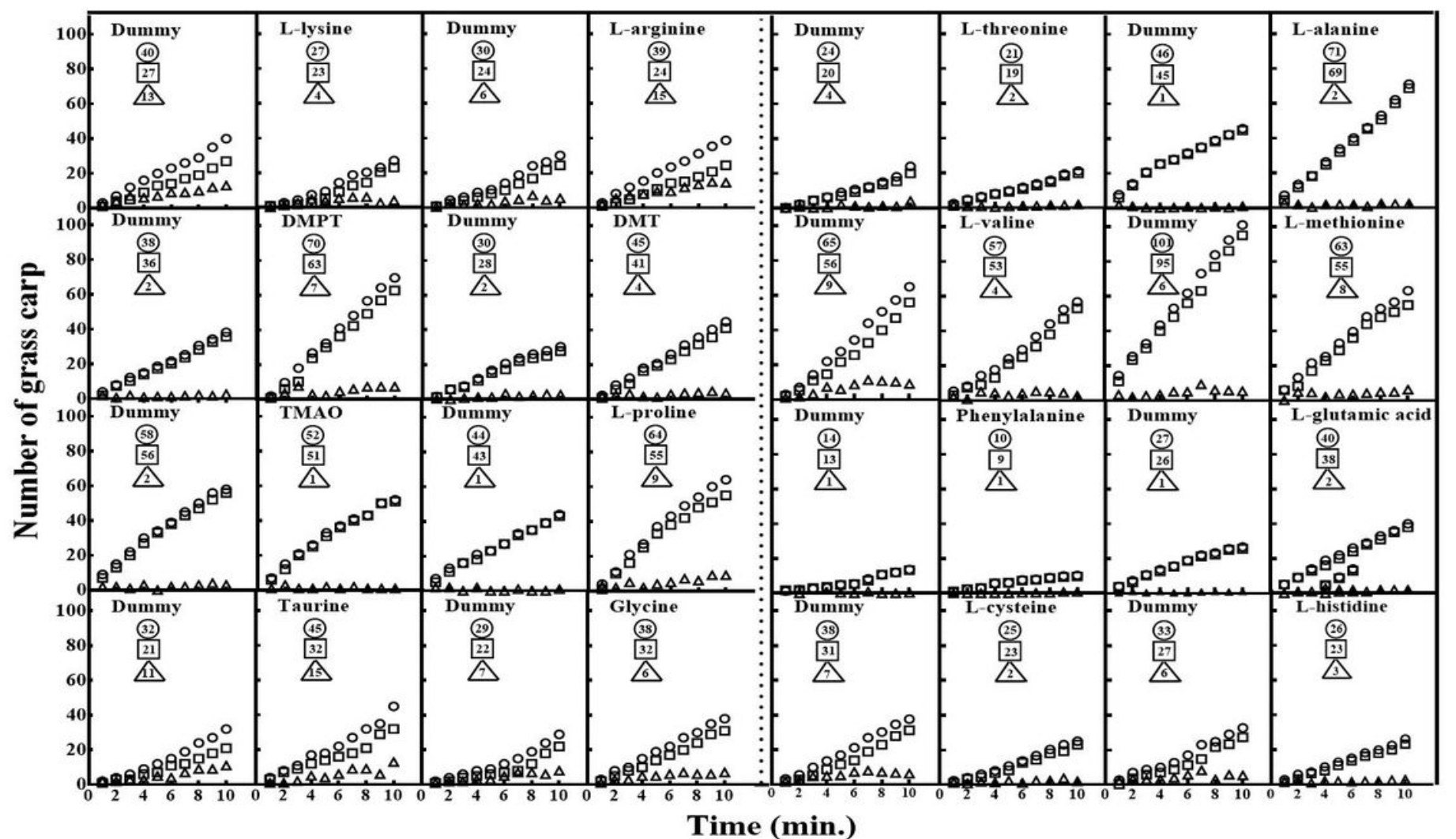

Figure 3

Time-course of the number of grass carp respondent to the stimuli in the maze test using 30 individuals. Values are the means of the triplicate observed values. Circle, triangle and square indicate the number of grass carp which entered (YE.i), left (YL.i) and remained (YR.i) in the test compartment, respectively. The numbers in the circle, triangle and square indicate the cumulative numbers of grass carp which entered (YE.i), left (YL.i) and remained (YR.i) in the test compartment at the end of the test.

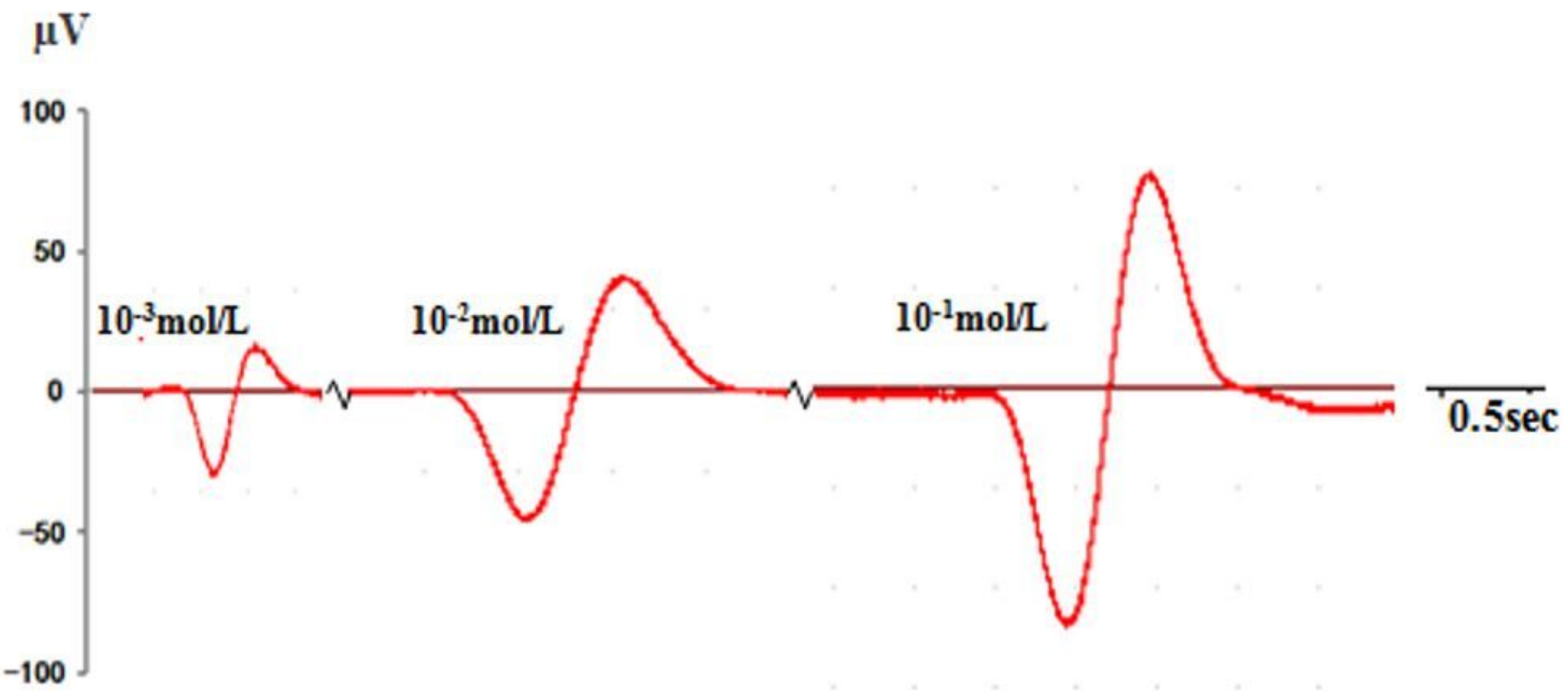

Figure 4

Electro-olfactogram (EOG) responses to a concentration series of taurine. 


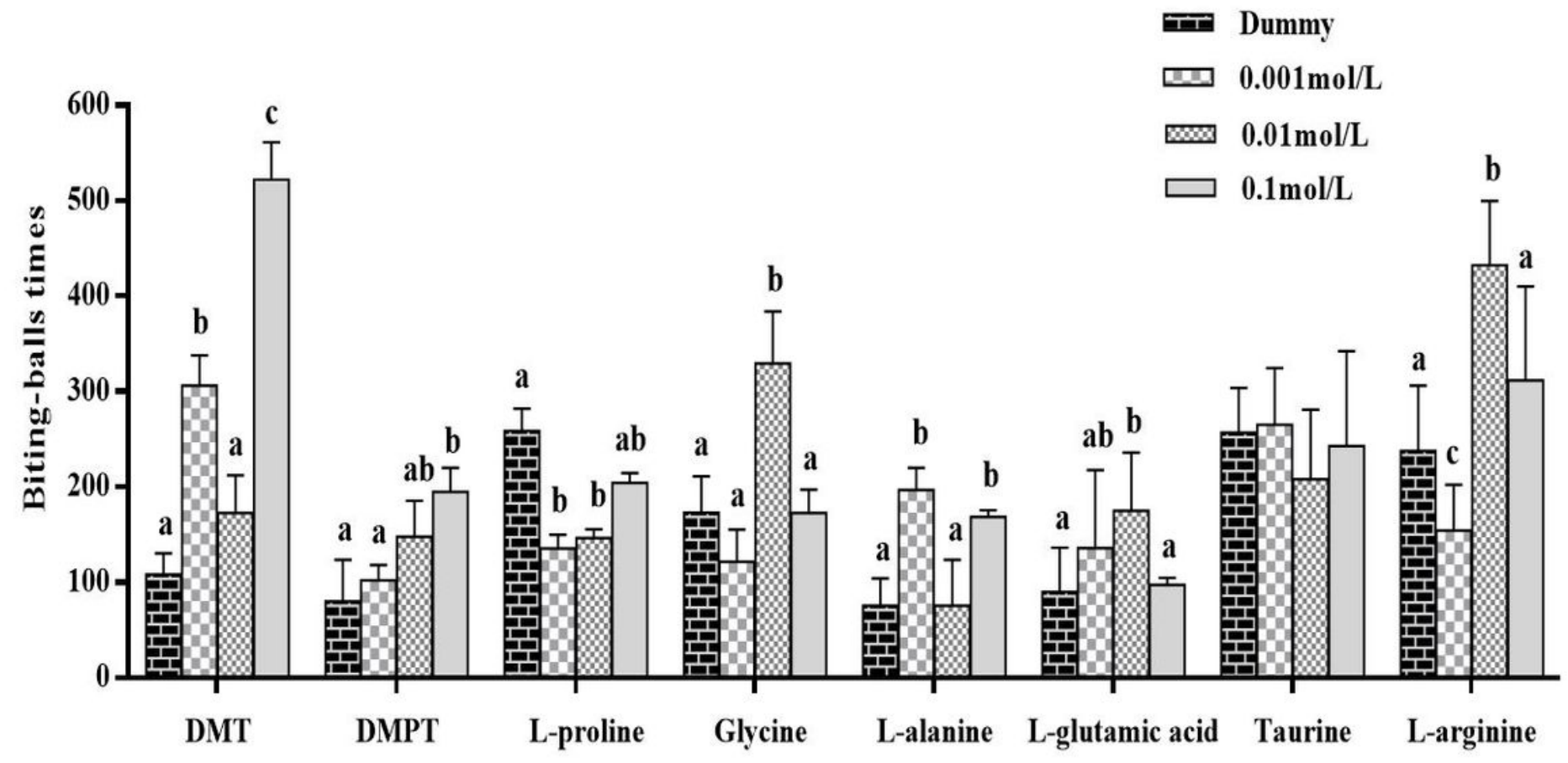

Figure 5

The biting-balls test result of grass carp responding to the 8 stimuli at 3 different concentrations. All data were expressed as means \pm SE ( $n=3$ ). Different letters indicate significant differences between different concentrations $(P<0.05)$. 

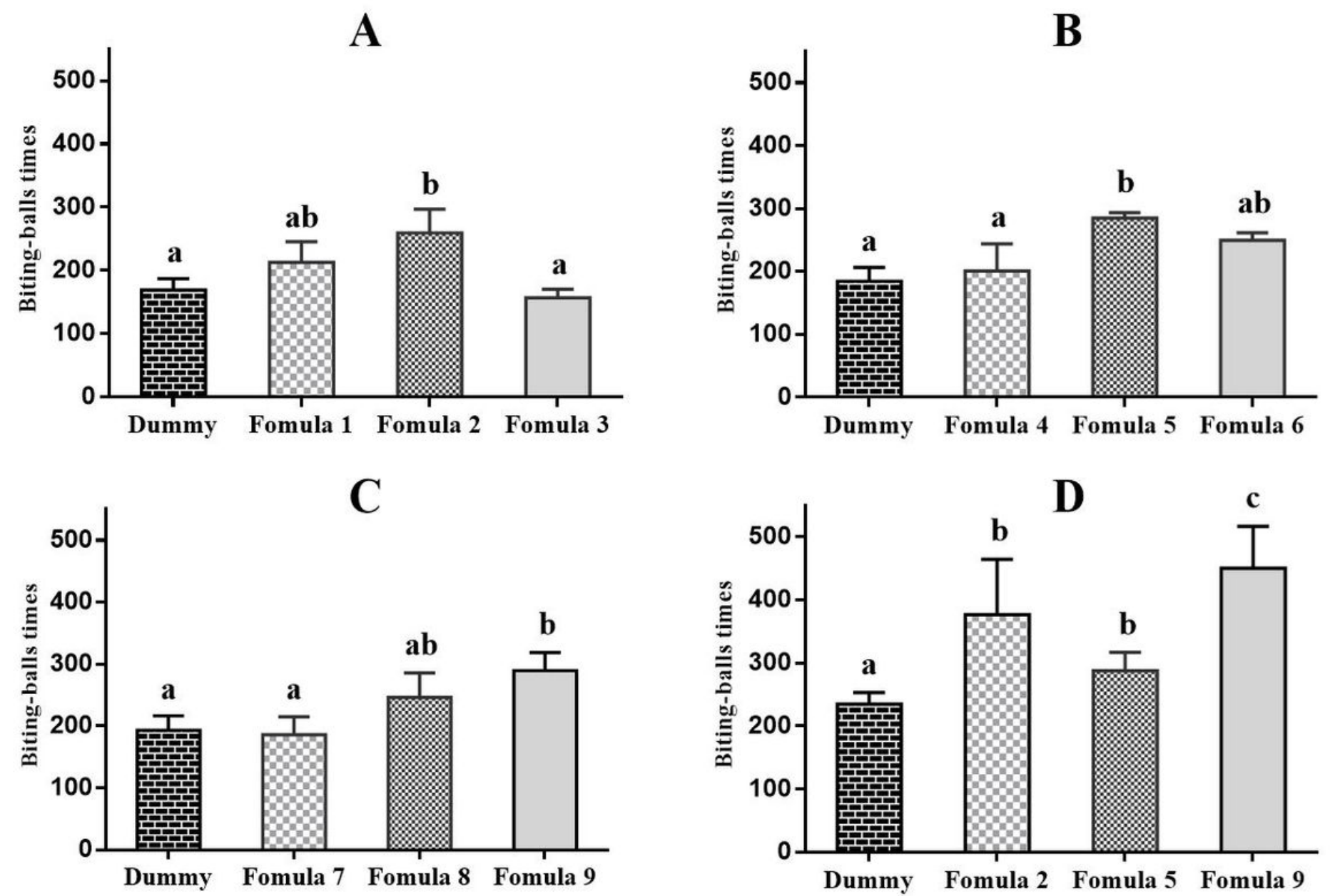

Figure 6

Comparison of biting times of grass carp responding to 9 different formulas. All data were expressed as means $\pm S E$ ( $n=3$ ). Different letters indicate significant differences $(P<0.05)$. The 9 formulas were divided into three groups. Three formulas in each group were compared with a dummy ball to get fig. $6 \mathrm{~A}, 6 \mathrm{~B}$ and $6 \mathrm{C}$. Finally, the formula with the most times of biting-balls in the three groups was compared with a dummy ball to get fig. $6 \mathrm{D}$. 